\title{
A challenging case of tuberculous peritonitis
}

\author{
Petru Emil Muntean'모 ${ }^{1}$, Andrada Mateutiu ${ }^{2}$ \\ 'Emergency Hospital of Arges County, Pitesti, Romania \\ ${ }^{2}$ Spitalul Clinic Municipal „Dr.Gavril Curteanu” Oradea, Romania
}

A 24-year-old female was admitted to the hospital for recurring irregularities of menstruation and a nine day history of abdominal tenderness. Physical exam revealed an abnormal build-up of fluid in the abdomen. Lab results within normal range. Normal chest X-ray. Abdominal ultrasound displayed ascites and nodular peritoneal thickening (Figure 1). Abdominal paracentesis exposed an exudative effusion, lymphocyte-rich inflammatory cells, no malignant cells and an adenosine deaminase level of 59 U/L. QuantiFERON-TB Gold test negative and also HIV-negative. Cancer antigen 125 level of 98.70, carcinoembryonic antigen level of 0.46, carcinoma antigen 15-3 level of 19.87, alpha-fetoprotein level of 1.99, cancer antigen 19-9 level of 0.99. Magnetic resonance imaging of the abdomen disclosed ascites and bilateral nodular opacities in the peritoneum. Ultrasound-guided tru-cut biopsy from nodular opacities expressed tuberculoid granulomas [1, 2]. According to our national guidelines, received a standard anti-TB regimen [3]. After six months, good clinical response. Tuberculous peritonitis is a rare condition which may simulate malignancy. TB ascites is an exudative pleural effusion as in the presence of a malignant tumour. Both illnesses have plenty correlations regarding lab results, imaging features and symptoms. Tuberculous peritonitis is accountable for approximately $1 \%$ of all tuberculosis cases [4]. In peritoneal carcinomatosis, CA125 level is elevated [5]. Early diagnosis of extrapulmonary tuberculosis responds well to the specific treatment and also prevents surgery.

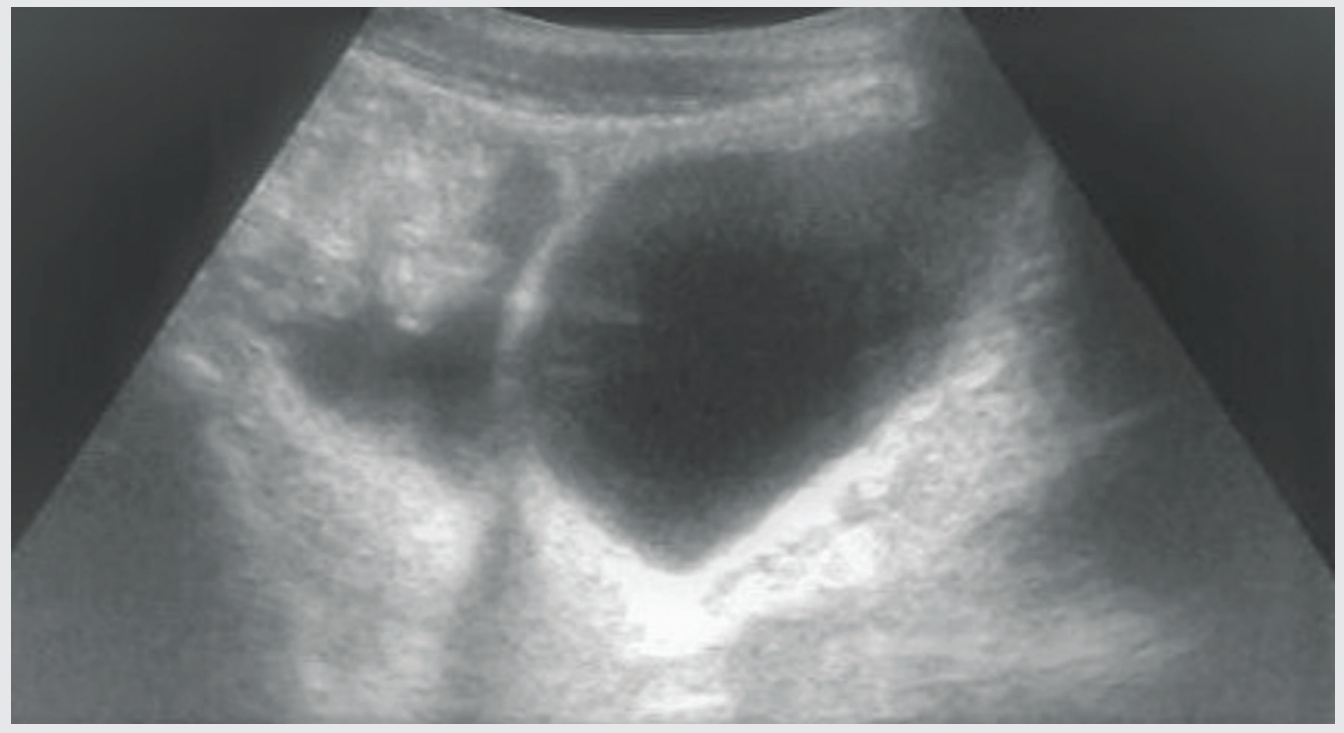

Figure 1. Abdominal ultrasound reported ascites in pelvis

Address for correspondence: Petru Emil Muntean, Str.1 Decembrie 1918, Cod Postal 405100 Campia Turzii, Cluj, e-mail: muntean.petruemil@yahoo.com Conflict of interest: None declared.

DOI: 10.5603/ARM.a2021.0111 | Received: 03.06.2021 | Copyright (C 2021 PTChP | ISSN 2451-4934 | e-ISSN 2543-6031

This article is available in open access under Creative Common Attribution-Non-Commercial-No Derivatives 4.0 International (CC BY-NC-ND 4.0) license, allowing to download articles and share them with others as long as they credit the authors and the publisher, but without permission to change them in any way or use them commercially. 


\section{References:}

1. Muntean P. Isolated intestinal tuberculosis associated with human immunodeficiency virus infection. Archives of the Balkan Medical Union. 2020; 55(1): 168-173, doi: 10.31688/abmu.2020.55.1.22.

2. Muntean PE. A rare case of a tuberculosis patient with sarcoidosis. Folia Med (Plovdiv). 2019; 61(2): 312-316, doi: 10.2478/folmed-2018-0055, indexed in Pubmed: $\underline{31301651 .}$

3. Muntean PE. A 50-year-old male with fever, cough, dyspnoea, chest pain, weight loss and night sweats. Breathe (Sheff). 2018; 14(1): 43-48, doi: 10.1183/20734735.013317, indexed in Pubmed: 29515667.

4. Peto HM, Pratt RH, Harrington TA, et al. Epidemiology of extrapulmonary tuberculosis in the United States, 1993-2006. Clin Infect Dis. 2009; 49(9): 1350-1357, doi: 10.1086/605559, indexed in Pubmed: 19793000.

5. O'Riordan DK, Deery A, Dorman A, et al. Increased CA 125 in a patient with tuberculous peritonitis: case report and review of published works. Gut. 1995; 36(2): 303-305, doi: 10.1136/gut.36.2.303, indexed in Pubmed: $\underline{783234}$. 